\title{
Associations between children's behavioural and emotional development and objectively measured physical activity and sedentary time: Findings from the UK Millennium Cohort Study
}

\author{
Lucy J Griffiths University College London Institute of Child Health, UK \\ lucy.griffiths@ucl.ac.uk \\ Marco Geraci University of South Carolina, USA \\ Mario Cortina-Borja University College London Institute of Child Health, UK \\ Francesco Sera University College London Institute of Child Health, UK \\ Catherine Law \\ University College London Institute of Child Health, UK \\ Heather Joshi \\ Andrew Ness \\ University College London Institute of Education, UK \\ University Hospitals Bristol NHS Foundation Trust and the University of Bristol, and \\ Bristol Dental School, UK \\ Carol Dezateux University College London Institute of Child Health, UK
}

(Received April $2015 \quad$ Revised November 2015)

http://dx.doi.org/10.14301/llcs.v7i2.353

\section{Abstract}

Physical activity (PA) can have a positive influence on mental health. Less is known about the influence of mental health on current and later PA and sedentariness in childhood. This study investigated cross-sectional and distal associations between behavioural and emotional development, and objectively measured moderate-to-vigorous PA (MVPA) and sedentary time, in seven-year-old children participating in the Millennium Cohort Study ( $n=6,497)$. Markers of behavioural/emotional development (scores for total difficulties, internalising and externalising problems) were obtained using the Strengths and Difficulties Questionnaire at ages three, five and seven years. Associations between sedentary time or MVPA (outcomes) and behavioural/emotional development (exposures) were analysed using median regressions, stratified by sex. In cross-sectional analyses, boys' sedentary time decreased with higher total difficulties scores (-1.1 minutes/day per score unit), boys' and girls' sedentary time decreased with higher externalising scores (-2.3 minutes/day per unit), and girls with higher internalising scores were more sedentary (1.4 minutes/day per unit). In analyses of MVPA, boys and girls were marginally more active with higher externalising scores (0.4 and 0.5 minutes/day per unit), and boys were less active for higher internalising scores (-0.7 minutes/day per unit). Distal associations showed similar patterns: children with increasing total difficulty and externalising scores at all ages were less sedentary at age seven; girls with increasing internalising scores particularly so. Boys and girls with increasing externalising scores were more active at age seven, whilst increasing internalising scores reduced MVPA for boys. In conclusion, behavioural/emotional development is associated with mid-childhood sedentary time and, more weakly, MVPA; this is of relevance to public health interventions aimed at increasing activity levels and the wellbeing of our young people.

\section{Keywords}

Physical activity, sedentary behaviour, accelerometry, mental health, child, cohort study 


\section{Introduction}

Approximately one in ten young people currently have a mental health disorder in the United Kingdom (Green, McGinnity, Meltzer, Ford, \& Goodman, 2004) and the United States (Merikangas et al., 2010). Physical activity has beneficial effects on psychological wellbeing in children and young people (Harden et al., 2001; Ussher, Owen, Cook, \& Whincup, 2007). Reduced levels of anxiety, depression, and behavioural problems and higher self-esteem are reported in children and adolescents who are physically active (Calfas \& Taylor, 1994; Ekeland, Heian, \& Hagen, 2005; Gruber, 1986; Larun, Nordheim, Ekeland, Hagen, \& Heian, 2006; Mutrie \& Parfitt, 1998;) and these associations are more marked for boys than girls (Sagatun, Sogaard, Bjertness, Selmer, \& Heyerdahl, 2007; Sebire et al., 2011).

Conversely, less is known about the psychological influences on physical activity or sedentary time at a population level, although selfesteem and physical self-perceptions are important for motivation and involvement in physical activity (Biddle \& Armstrong, 1992; Crocker, Eklund, \& Kowalski, 2000; Raustorp, Mattsson, Svensson, \& Stahle, 2006). There is growing, albeit limited, evidence from cross-sectional studies that internalising problems are associated with lower, and externalising problems with higher, levels of physical activity (Brodersen, Steptoe, Williamson, \& Wardle, 2005; Gosmann et al., 2015; van EgmondFrohlich, Weghuber, \& de, 2012). Evidence linking internalising problems like depression (Stavrakakis, de Jonge, Ormel, \& Oldehinkel, 2012; Van Der, Paw, Twisk, \& Van, 2007) or other mental health problems with later physical activity is inconclusive.

Pathways linking behavioural and emotional development with physical activity and sedentary time are likely to be complex and may have bidirectional relationships over the life course. Evidence from longitudinal studies starting in early life is lacking and is needed to shed light on pathways linking social and emotional wellbeing in early life and activity (Department of Health, 2011; National Institute for Health and Clinical Excellence, 2008; U.S. Department of Health and Human Services, 2008).

This paper examines associations between recent parental report of behavioural and emotional development and objective measures of physical activity and sedentary time in seven-year old children living in the United Kingdom (UK), recruited to a longitudinal study in infancy and in whom earlier reports of behavioural and emotional development had also been obtained at ages three and five years. We analysed cross-sectional and distal associations between recent and earlier behavioural and emotional development, and objectively measured activity and sedentariness at age seven years. Based on evidence from existing literature we hypothesised that children with higher recent total difficulties and externalising scores would be less sedentary and more active; that those with higher recent internalising scores would be more sedentary and less active; and that these relationships would also be found when these facets of development were measured earlier and at repeated time-points.

\section{Methods}

\section{Participants and procedures}

We used data from the Millennium Cohort Study (MCS), a national longitudinal study of the social, economic and health-related circumstances of children living in the UK. Children were recruited between September 2000 and January 2002 when aged nine months (Smith \& Joshi, 2002) using a disproportionately stratified clustered sampling design to over-represent children living in Wales, Scotland and Northern Ireland, disadvantaged areas and areas with high proportions of ethnic minority groups. The original cohort comprised 18,818 children (an estimated $72 \%$ of those approached) whose parents were first interviewed at home when their child was aged nine months (MCS1). Our analyses used data collected at this first survey as well as at subsequent interviews carried out when children were aged three (MCS2), five (MCS3) and seven (MCS4) years. Objective measures of physical activity and sedentary time were made following the interview at age seven. Although further interviews have been carried out at age 11 and 14, these data were not available at the time of this analysis. We obtained the MCS data from the UK Data Service. The MCS was approved by the South West Multi-Centre Research Ethics Committee (MCS1), London Multi-Centre Research Ethics Committee (MCS2 and MCS3) and the Northern and Yorkshire Multi-Centre Research Ethics Committee (MCS4).

\section{Outcome variables: objectively measured}




\section{physical activity and sedentary time}

Physical activity and sedentary time were measured objectively using the Actigraph GT1M accelerometer (Actigraph, Pensacola, Florida), a small and lightweight, non-waterproof device, which was worn on an elastic belt around the child's waist. The Actigraph GT1M has been extensively validated in children and compares favourably against observational techniques (Fairweather, Reilly, Grant, Whittaker \& Paton, 1999), heart rate monitoring (Ott, Pate, Trost, Ward, \& Saunders, 2000), indirect and room calorimetry (Puyau, Adolph, Vohra, \& Butte, 2002; Trost et al., 1998) and doubly labelled water techniques (Ekelund, Yngve, Brage, Westerterp, \& Sjostrom, 2004). It has been shown to be robust when used in other largescale physical activity studies in children (Riddoch et al., 2004, 2007; Troiano et al., 2008). The units of measurement reported from the accelerometer are called "counts" and these are then summarised by epochs, which in our case spanned 15 seconds.

A total of 13,681 singleton children were interviewed at age seven years in the MCS and invited to participate in the accelerometry study, which took place over a 15-month period between May 2008 and August 2009 after the completion of the MCS4 interviews. Those who consented $(12,872 ; 94.5 \%)$ were posted an accelerometer, programmed to collect and aggregate data over 15second epochs. Participants were instructed to position the monitor on top of their right hip, fitted tightly but comfortably to their body, either on top of indoor clothing or against their skin. They were asked to start wearing their accelerometer the morning after they received it and to continue doing so during waking hours for seven days. They were asked to remove the monitor when bathing or swimming. The accelerometer measurements commenced only after the MCS4 interviews had been initiated, resulting in a median interval of 36 weeks (interquartile range (IQR) 29 - 45) between the MCS4 interview and the date accelerometers were worn. Letters reminding participants to wear and return their accelerometer were sent out, as detailed previously (Rich et al., 2013b).

Accelerometers were returned from 9,772 singleton children (75.9\% of those who consented). Data were downloaded using Actigraph software version 3.8.3 (Actigraph, Pensacola, Florida) and processed using the package pawacc (Geraci, 2012; Geraci et al., 2012) for the R statistical computing environment ( $R$ Development Core Team, 2014). Non-wear time was defined as any time period of consecutive zero-counts lasting 20 minutes or more: these periods were removed from the summation of activity. In addition, we removed moderate-to-vigorous physical activity (MVPA) values $\geq 11715$ counts per minute (cpm) from the dataset, based on a reliability study (Rich et al., 2014) that indicated that count values above this threshold were extreme and likely to be spurious. Only days with ten hours or more of recorded time were retained in the dataset, and only participants with at least two such days (week or weekend days) were included in the analyses (Rich et al., 2013a). The application of these criteria resulted in a sample size of 6,497 singleton children. Reliable accelerometer data were less likely to be acquired from children who were: male; overweight/obese; white, mixed or 'other' ethnicity; living in disadvantaged areas; had less educated mothers and/or lone mothers (Rich et al., 2013b). However, overall, the differences in demographic characteristics between our analytic sample and the whole cohort sample interviewed at age seven were small (Griffiths et al., 2013a).

For each child, mean daily minutes spent in sedentary time (defined as $<100 \mathrm{cpm}$ ) and in MVPA (2240 to $11715 \mathrm{cpm}$ ) were calculated, and both standardised for child's total wear time (Griffiths et al., 2013b). The cut-off points used to define the physical intensity thresholds were those determined in a calibration study in children of a similar age (Pulsford et al., 2011).

\section{Exposure variables: total difficulties, internalising and externalising problems}

At ages three, five and seven years, the main respondent ( $97 \%$ were natural mothers at MCS4) completed the Strengths and Difficulties Questionnaire (SDQ), which provides a measure of emotional and behavioural problems in children; this tool has high test-retest reliability and good validity (Goodman, 1997), and has been used in other large epidemiological studies in this age group (Goodman, Ford, Simmons, Gatward, \& Meltzer, 2000; Wiles et al., 2006).

The SDQ includes 20 items relating to (i) conduct problems, (ii) hyperactivity and inattention problems, (iii) emotional symptoms, and (iv) peerrelationship problems (Figure 1). These (i-iv) were summed to create a 'total difficulties' score 
bounded between 0 and 40, with higher scores indicating more difficulties. In addition, subscales (i) and (ii), and subscales (iii) and (iv) were summed to obtain, respectively, externalising and internalising problem scores, both with maximum conceivable scores of 20; these broader subscales are recommended for analyses in non-clinical populations (Goodman, Lamping, \& Ploubidis, 2010). SDQ total difficulties score, internalising and externalising problem scores were therefore used as exposure variables. Cronbach's alpha coefficients were calculated for these variables at ages three, five and seven years; they were as follows: total difficulties scores $(0.76,0.7$ and 0.80 , respectively); internalising problem scores $(0.58,0.65$, and 0.69$)$; and externalising problem scores $(0.77,0.77$, and 0.79). One unit on any of these scores is the equivalent of a difficulty / problem being 'somewhat true' rather than 'not true', or the difference between it being 'certainly true' rather than 'somewhat true'. 
Figure 1: Strengths and Difficulties Questionnaire items and groupings

\section{Conduct Problems}

Often has temper tantrums or hot tempers

Generally obedient, usually does what adults request*

Often fights with other children or bullies them

Often lies or cheats

Steals from home, school or elsewhere

\section{Hyperactivity / inattention problems}

Restless, overactive, cannot stay still for long

Constantly fidgeting or squirming

Easily distracted, concentration wanders

Thinks things out before acting*

Sees tasks through to the end, good attention span*

\section{Emotional symptoms}

Often complains of headaches, stomach aches or sickness

Many worries or often seems worried

Often unhappy, down-hearted or tearful

Nervous or clingy in new situations, easily loses confidence

Many fears, easily scared

\section{Peer relationship problems}

Rather solitary, tends to play alone

Has at least one good friend*

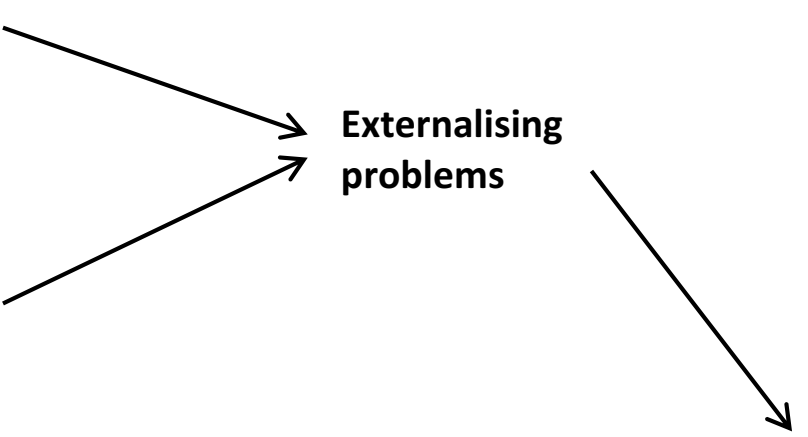

Generally liked by other children*

Picked on or bullied by other children

Gets on better with adults than other children

* SDQ items are scored on a 0-2 scale (not true, somewhat true, certainly true). Items denoted here with ${ }^{* \prime}$ are reversely scored. 


\section{Confounding factors}

Information on confounding factors was collected from the first four MCS surveys. These included cohort child's ethnicity, prevalence of a longstanding illness (if main respondents reported at least once at MCS2-4 that their child had any illness or disabilities that had troubled them over a period of time) and body mass index (BMI: $\mathrm{kg} / \mathrm{m}^{2}$ ) derived from direct measurement. In addition, we included relative poverty captured at age seven (a binary variable denoting whether net equivalised family income, before housing costs, was below $60 \%$ of the national median (Bradshaw \& Holmes, 2010)) and maternal psychological distress, measured using the Kessler- 6 scale (Kessler et al., 2002). In the following, we refer to $\mathrm{BMI}$, relative poverty, and maternal distress as time-varying confounders (i.e., confounders whose values can change over time).

\section{Statistical analyses}

Linear regression models were fitted to assess the association between behavioural and emotional development scores and sedentary time or MVPA levels. Given the non-normality and heteroscedasticity (i.e., non-constant variance) in the error terms, we used median rather than mean regression (Geraci, 2013). The former leads to valid inference without assuming a specific probability distribution for the error. The interpretation of the median regression coefficients is analogous to that seen in other types of regression analysis, i.e. the 'slope' measures the expected change in the conditional median outcome for a one-unit increase in the corresponding predictor, holding all other variables at any fixed value. Ethnicity, longstanding illness, and relative poverty were entered in the models as categorical variables, with SDQ scores, $\mathrm{BMI}$, and maternal distress entered as continuous variables.

Analyses were stratified by sex given established differences in activity levels between boys and girls in this sample (Griffiths et al., 2013a), including gender differences within ethnic group $(p<0.001)$ and gender differences in children of Pakistani origin as compared to those in White children $(p=$ 0.001). Two types of analyses were performed distinguished by the ages at which the behavioural and emotional development exposure variables (total difficulties, internalising and externalising scores) were measured. In the first set of analyses, the MVPA and sedentary time outcomes were analysed by examining the influence of exposure variables at age seven with and without adjustment for all confounding factors (including time-varying confounders) measured the same age only. These analyses are approximate cross-sectional analyses due to the interval noted above between the MCS4 interview and the accelerometer measurements.

In the second set of analyses, the MVPA and sedentary time variables were analysed as distal outcomes by examining background effects of the exposure variables at ages three, five and seven, with and without adjustment for all confounding factors (including time-varying confounders). We adopted the parameterisation for distal outcomes outlined by De Stavola et al (De Stavola et al., 2006, equation 5) and we defined the following median regression model:

$$
\begin{gathered}
\operatorname{Med}(Y)=a+\left(b_{3}+b_{5}+b_{7}\right) Z_{3}+\left(b_{5}+b_{7}\right)\left(Z_{5}-Z_{3}\right) \\
\quad+b_{7}\left(Z_{7}-Z_{5}\right) \\
=a+c_{1} Z_{3}+c_{2}\left(Z_{5}-Z_{3}\right)+c_{3}\left(Z_{7}-Z_{5}\right),(1)
\end{gathered}
$$

where $Z_{j}$ denotes the exposure measured at age $j, a$ is the model's intercept and the 'slopes' of the model measure (i) the cumulative effect of increasing the exposure at each age by one unit, that is, the sum of all conditional effects $c_{1}=$ $\left(b_{3}+b_{5}+b_{7}\right)$; (ii) the effect of increasing the exposure between ages three and five by one unit, with that change shifting the exposure at ages five and seven, which is the sum of the conditional effects $c_{2}=\left(b_{5}+b_{7}\right)$; and (iii) the effect of increasing the exposure between ages five and seven by one unit, with that change shifting the exposure at age seven only, i.e. the conditional effect $c_{3}=b_{7}$. Note that equation (1) is algebraically equivalent to the equation $\operatorname{Med}(Y)=$ $a+b_{3} Z_{3}+b_{5} Z_{5}+b_{7} Z_{7}$. The latter, however, does not provide a straightforward interpretation from a life-course epidemiology perspective (De Stavola et al., 2006). In contrast, the parameters $c_{1}, c_{2}$, and $c_{3}$ have a natural interpretation when measurements accumulate monotonically with age (e.g. height, head circumference etc.), in which case changes in the value of the exposure at a particular age imply a shift in the same direction of the exposure at subsequent ages. It should be stressed that lack of monotonicity is by no means a hindrance if the 
purpose is estimating trajectories that change direction over time (in this case, a linear combination of $c_{1}, c_{2}$, and $c_{3}$ will be sufficient). We assessed empirically (results not shown) changes in direction of SDQ score trajectories and found that only in about $20 \%$ of the cases was an increase (or decrease) between ages three and five followed by a decrease (or increase) between ages five and seven in externalising, internalising or total SDQ scores.

The MCS sampling design was accounted for in the estimation (Geraci, 2013), with probability weights adjusted for the non-response in the MCS1 through MCS4 surveys as well as for the nonresponse in the physical activity survey (Griffiths et al., 2013b). Standard errors of quantile regression coefficients were computed using a bootstrap approach based on 100 replications (Geraci, 2013). Given the presence of missing values, the regression analyses were performed on five imputed datasets. Final estimates and standard errors were then computed according to Rubin's rules. A summary of the missing data as well as the multiple imputation approach are described as follows.

As a result of the data selection procedure, the outcome variables were fully observed. However, exposure variables were not completely observed. In particular, the percentages (out of 6,497 children) of missing values for emotional problems score were $8.5,4.3$, and $1.5 \%$ in sweeps MCS2, MCS3 and MCS4, respectively. Similar proportions were observed for conduct problems score $(8.4,4.2$, $1.4 \%)$, hyperactivity score $(9.2,4.5,1.6 \%)$ and peer relationship problems score $(8.9,4.4,1.5 \%)$. As for time-varying confounders, there were missing values for $\mathrm{BMI}(17.3,3.4,1.0 \%)$, relative poverty $(17.3,3.0,<0.0 \%)$, and maternal distress $(18,8.5$, $2.8 \%$ ) (although the proportion of missing values for these variables declined from sweep to sweep, individual patterns of missing values were not monotonic). Longstanding illness was completely observed and ethnicity had only one missing value. Forty percent of children had at least one missing value; $11 \%$ had at least five missing values; only $2 \%$ had 10 or more missing values. Three children had 22 missing values, which was the maximum number observed.

Under the assumption of missing at random, we carried out a multiple imputation by chained equations (Geraci, 2013), with five iterations per chain. The matrix feeding into the imputation algorithm consisted of the outcome, the exposure and the confounding variables (26 variables in total), in addition to five auxiliary variables which were: two sampling design variables (probability weights adjusted for non-response and the MCS stratification variable) and SDQ scores for social behaviour (measured at ages three, five and seven). Continuous variables (SDQ scores, BMI, maternal distress) were imputed using quantile regression, while relative poverty was imputed using logistic regression. The only one missing value for ethnicity was imputed using polytomous regression.

The analyses were carried out using the $R$ packages quantreg (Koenker, 2012), survey (Lumley, 2004; Lumley, 2011), and mice (Van Buuren \& Groothuis-Oudshoorn, 2011). Statistical significance was set at the $5 \%$ level.

\section{Results}

\section{Subject characteristics}

Children were on average aged 7.5 years when they wore the accelerometers. Approximately half the children included in these analyses were girls $(n=3321 ; 51 \%)$ and most $(88 \%)$ were White (table 1). Parents of around one third reported them to have a longstanding illness at least once and one third of families were below the relative poverty threshold, comparable to the MCS4 sample as a whole (29.6\%) (Hansen, Jones, Joshi, \& Budge, 2010). The median score for maternal psychological distress was 2. The median score for BMI at age seven was 16.0 (IQR: 15.1 - 17.3), which is very close to the BMI presented for children of this age in UK growth charts (Royal College of Paediatrics and Child Health, 2013). 
Table 1: Sample characteristics

\begin{tabular}{|c|c|c|c|}
\hline \multirow[t]{2}{*}{ Variable } & $\begin{array}{l}\text { All children } \\
(n=6,497)\end{array}$ & $\begin{array}{c}\text { Girls } \\
(3,321)\end{array}$ & $\begin{array}{l}\text { Boys } \\
(3,176)\end{array}$ \\
\hline & \multicolumn{3}{|c|}{ Sample size (weighted percentage) } \\
\hline \multicolumn{4}{|c|}{$\begin{array}{l}\text { Child's ethnicity ( } 9 \text { months, } \\
\text { confirmed at } 3 \text { years) }\end{array}$} \\
\hline White & $5,711(87.9)$ & $2,917(87.9)$ & $2,794(88.0)$ \\
\hline Indian & $139(2.1)$ & $78(2.3)$ & $61(1.9)$ \\
\hline Pakistani & $177(2.7)$ & $84(2.5)$ & $93(2.9)$ \\
\hline Black & $142(2.2)$ & $71(2.1)$ & $71(2.2)$ \\
\hline Bangladeshi & $70(1.1)$ & $39(1.2)$ & $31(1.0)$ \\
\hline Mixed & $168(2.6)$ & $83(2.5)$ & $85(2.7)$ \\
\hline Other & $90(1.4)$ & $49(1.5)$ & $41(1.3)$ \\
\hline \multicolumn{4}{|c|}{ Longstanding illness (age 3, 5 or 7 ) } \\
\hline Yes & $1,991(31.4)$ & $929(28.6)$ & $1,062(34.0)$ \\
\hline No & $4,506(68.6)$ & $2,392(71.4)$ & $2,114(66.0)$ \\
\hline \multicolumn{4}{|l|}{ Poverty (age 7) } \\
\hline Above threshold* & $5,034(69.8)$ & $2,547(69.1)$ & $2,487(70.4)$ \\
\hline Below threshold & $1,463(30.2)$ & $774(30.9)$ & $689(29.6)$ \\
\hline
\end{tabular}

\section{Weighted median (lower quartile, upper quartile)}

SDQ scores

Total difficulties (age 3)

Total difficulties (age 5)

Total difficulties (age 7)

Externalising problems (age 3 )

Externalising problems (age 5)

Externalising problems (age 7)

Internalising problems (age 3)

Internalising problems (age 5)

Internalising problems (age 7)

Child's Body Mass Index (age 7)

Maternal psychological distress

(age 7)**

Sedentary time mins/day

MVPA mins/day

$$
\begin{aligned}
& 9(6,13) \\
& 6(4,10) \\
& 6(3,10) \\
& 6(4,9) \\
& 4(2,7) \\
& 4(2,7) \\
& 2(1,4) \\
& 2(1,3) \\
& 2(1,4)
\end{aligned}
$$

$16.0(15.1,17.3) \quad 16.1(15.1,17.4)$

$2(0,4)$

$2(0,4)$

$391(358,424)$

$400(367,432)$

$6(5,12)$

$9(6,13)$

$7(4,11)$

$7(4,11)$

$6(3,9)$

$7(4,10)$

$4(2,6)$

$5(3,7)$

$5(3,7)$

$2(1,4)$

$2(1,4)$

$2(1,4)$

$16.0(15.1,17.2)$

$60(47,76)$ $54(43,67)$
$2(0,4)$

$384(351,415)$

$67(53,84)$

* Threshold: $60 \%$ of the national median.

** Measured using the Kessler-6 scale (Kessler et al., 2002).

Missing observations (all children): Ethnic group (1); Poverty (1); Total difficulties age 3 (684); Total difficulties age 5 (315); Total difficulties age 3 (122); Externalising problems age 3 (608); Externalising problems age 5 (296) Externalising problems age 7 (108); Internalising problems age 3 (596); Internalising problems age 5 (291) Internalising problems age 7 (104); Child's BMI (67); Maternal distress (179). 
Median total difficulties and externalising scores reported by parents were higher at age three than ages five and seven (table 1). Median internalising scores were the same at all three ages. Distributions were skewed towards higher values for all scores.

Children spent a median of 60 minutes (IQR: 4776) each day in MVPA and this was higher in boys (67 mins/day; IQR: $53-84$ ) than girls (54 mins/day, IQR: $43-67)$. Approximately $50 \%$ of children were sedentary for six and a half hours or more each day (IQR: 358 - 424 median mins/day), with girls (400 mins/day; IQR: 367 - 432) slightly more sedentary than boys (384 mins/day; IQR: $351-415$ ).

\section{Cross-sectional associations of behavioural and emotional development}

The results of the first set of median regression analyses are reported in table 2. The regression coefficients associated with the exposures are expressed in minutes/SDQ-score unit.

Boys with higher total difficulty scores were less sedentary: median daily sedentary time in boys decreased by 1.1 minutes for each unit increase on the total score scale at seven years, $(p<0.001)$. Thus, for example, the predicted median time spent being sedentary each day was 381.0 minutes for boys with a total score of 7 , as opposed to 388.7 minutes for boys with a total score of 0 . Boys and girls with higher externalising scores had lower median sedentary time (-2.3 daily minutes/unit score for both boys and girls, $p<0.001)$. In contrast, girls with higher internalising scores were more sedentary (1.4 daily minutes/unit score, $p=0.01$ ); the median sedentary time each day for girls with an internalising score of 2 is estimated to be 2.8 minutes a day greater relative to those with zero scores, a predicted median time of 402.5 compared with 399.7 minutes.

Boys and girls with higher externalising scores engaged in slightly more MVPA (0.4 daily minutes/unit score, $p=0.025 ; 0.5$ minutes/unit score, $p=0.005$, respectively) but this association was not seen for total difficulties scores. Conversely, boys, but not girls, with higher internalising scores had lower median MVPA (-0.7 daily minutes/unit score, $p=0.029$ ). 
Table 2: Results of adjusted ${ }^{a}$ median regression cross-sectional analyses. Estimates and standard errors are expressed as minutes per day per unit SDQ score.

\begin{tabular}{|c|c|c|c|c|c|c|c|}
\hline & & \multicolumn{3}{|c|}{ Sedentary time } & \multicolumn{3}{|c|}{ MVPA } \\
\hline & & Estimate & SE & $p$-value & Estimate & SE & $p$-value \\
\hline \multirow[t]{2}{*}{ Boys } & Intercept & 388.7 & 2.4 & $<0.001$ & 64.8 & 1.3 & $<0.001$ \\
\hline & Total difficulties (age 7) & -1.1 & 0.3 & $<0.001$ & 0.1 & 0.1 & 0.677 \\
\hline \multirow[t]{2}{*}{ Girls } & Intercept & 404.9 & 4.0 & $<0.001$ & 51.5 & 1.1 & $<0.001$ \\
\hline & Total difficulties (age 7) & -0.6 & 0.5 & 0.229 & 0.2 & 0.1 & 0.288 \\
\hline \multirow[t]{2}{*}{ Boys } & Intercept & 391.1 & 2.5 & $<0.001$ & 63.7 & 1.2 & $<0.001$ \\
\hline & Externalising problems (age 7) & -2.3 & 0.5 & $<0.001$ & 0.4 & 0.2 & 0.025 \\
\hline \multirow[t]{2}{*}{ Girls } & Intercept & 408.9 & 3.1 & $<0.001$ & 50.6 & 1.1 & $<0.001$ \\
\hline & Externalising problems (age 7) & -2.3 & 0.6 & $<0.001$ & 0.5 & 0.2 & 0.005 \\
\hline \multirow[t]{2}{*}{ Boys } & Intercept & 381.5 & 2.0 & $<0.001$ & 65.7 & 1.3 & $<0.001$ \\
\hline & Internalising problems (age 7) & 0.0 & 0.7 & 0.975 & -0.7 & 0.3 & 0.029 \\
\hline \multirow[t]{2}{*}{ Girls } & Intercept & 399.7 & 3.1 & $<0.001$ & 52.5 & 1.0 & $<0.001$ \\
\hline & Internalising problems (age 7) & 1.4 & 0.6 & 0.011 & -0.3 & 0.2 & 0.157 \\
\hline
\end{tabular}

Table abbreviations: MVPA, moderate to vigorous physical activity; SE, standard error.

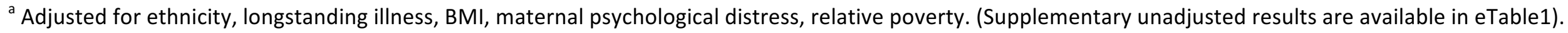

Note: Baseline for all models: white ethnic group, no longstanding illness, $\mathrm{BMI}=8$, Kessler $=0$, above $60 \%$ poverty line, all score variables $=0$. 


\section{Associations of distal sedentary time and MVPA outcomes with age-related changes in behavioural and emotional development}

Overall, distal associations of sedentary time and age-related changes in behavioural and emotional development were more consistent and stronger for sedentary time than for MVPA (table 3). Increasing total difficulties scores at all ages were associated with a reduction in median sedentary time; the cumulative effects were of similar magnitude in boys (-1.1 minutes/unit score, $p=$ $0.01)$ and girls $(-1.2, p=0.03)$. Similarly, boys experienced a reduction in median sedentary time for a change in total difficulties score between ages five and seven $(-1.2, p<0.001)$. A one unit increase in externalising problem scores at all ages was associated with 2.5 fewer minutes in median sedentary time for boys $(p<0.001)$ and 3.3 fewer minutes for girls $(p<0.001)$. This diminution in sedentary time was also seen in relation to increasing externalising problem scores for both boys and girls between the ages of three and five $(-2.0$ minutes/unit score for boys $(p=0.002)$ and -2.4 daily minutes/unit score for girls $(p=0.001))$, but in boys only for increasing externalising problem scores between ages five and seven (-2.0 daily minutes/unit score, $p=0.001)$. In contrast, an association between increasing internalising problem scores and sedentary time was only observed in girls: a one unit increase in internalising scores at all ages, and between ages five and seven, was associated with an increase of 1.8 minutes $(p=0.034)$ and 1.6 minutes $(p=0.029)$, respectively, in median sedentary time at age seven.

No substantial association was observed between total difficulty scores and MVPA in these analyses (table 3). However, a small increase in median MVPA time with increasing externalising problems at all ages was seen in boys $(0.9, p=$ $0.001)$ and girls $(0.6, p=0.006)$. Increasing the score of internalising problems in boys by one unit between ages three and five was associated with a decrease of 1.0 minute $(p=0.001)$ in daily MVPA at age seven. 
Table 3: Results of adjusted ${ }^{\mathrm{a}}$ median regression analyses with sedentary time and moderate-to-vigorous physical activity as distal outcomes. Estimates and standard errors are expressed as minutes per day per unit SDQ score.

\begin{tabular}{|c|c|c|c|c|c|c|c|}
\hline & & \multicolumn{3}{|c|}{ Sedentary time } & \multicolumn{3}{|c|}{ MVPA } \\
\hline & & Estimate & SE & $p$-value & Estimate & SE & $p$-value \\
\hline \multirow[t]{4}{*}{ Boys } & Total difficulties intercept & 389.6 & 3.6 & $<0.001$ & 62.1 & 1.6 & $<0.001$ \\
\hline & Total difficulties (sum of conditional effects at ages $3,5,7$ ) & -1.1 & 0.4 & 0.010 & 0.3 & 0.2 & 0.095 \\
\hline & Total difficulties (sum of conditional effects at ages 5 and 7) & -0.9 & 0.5 & 0.053 & -0.2 & 0.2 & 0.233 \\
\hline & Total difficulties (conditional effect at age 7) & -1.2 & 0.3 & $<0.001$ & -0.1 & 0.2 & 0.522 \\
\hline \multirow[t]{4}{*}{ Girls } & Total difficulties intercept & 408.4 & 4.5 & $<0.001$ & 51.7 & 1.3 & $<0.001$ \\
\hline & Total difficulties (sum of conditional effects at ages $3,5,7$ ) & -1.2 & 0.6 & 0.030 & 0.2 & 0.2 & 0.284 \\
\hline & Total difficulties (sum of conditional effects ages 5 and 7) & -0.7 & 0.6 & 0.261 & 0.2 & 0.2 & 0.286 \\
\hline & Total difficulties (conditional effect at age 7) & 0.4 & 0.6 & 0.520 & 0.1 & 0.2 & 0.727 \\
\hline \multirow[t]{4}{*}{ Boys } & Externalising problems intercept & 392.8 & 3.4 & $<0.001$ & 59.8 & 1.5 & $<0.001$ \\
\hline & Externalising problems (effects at ages $3,5,7$ ) & -2.5 & 0.6 & $<0.001$ & 0.9 & 0.2 & 0.001 \\
\hline & Externalising problems (effects at ages 5 and 7) & -2.0 & 0.6 & 0.002 & 0.3 & 0.3 & 0.389 \\
\hline & Externalising problems (effects at age 7) & -2.0 & 0.6 & 0.001 & 0.0 & 0.3 & 0.995 \\
\hline \multirow[t]{4}{*}{ Girls } & Externalising problems intercept & 414.3 & 3.5 & $<0.001$ & 50.2 & 1.4 & $<0.001$ \\
\hline & Externalising problems (effects at ages $3,5,7$ ) & -3.3 & 0.7 & $<0.001$ & 0.6 & 0.2 & 0.006 \\
\hline & Externalising problems (effects at ages 5 and 7) & -2.4 & 0.7 & 0.001 & 0.5 & 0.3 & 0.079 \\
\hline & Externalising problems (effects at age 7) & -0.7 & 0.8 & 0.385 & 0.4 & 0.3 & 0.167 \\
\hline \multirow[t]{4}{*}{ Boys } & Internalising problems intercept & 379.7 & 2.2 & $<0.001$ & 65.8 & 1.4 & $<0.001$ \\
\hline & Internalising problems (effects at ages $3,5,7$ ) & 0.7 & 0.7 & 0.292 & -0.6 & 0.4 & 0.141 \\
\hline & Internalising problems (effects at ages 5 and 7) & 0.4 & 0.7 & 0.536 & -1.0 & 0.3 & 0.001 \\
\hline & Internalising problems (effects at age 7) & -0.7 & 0.7 & 0.356 & -0.4 & 0.4 & 0.285 \\
\hline \multirow[t]{4}{*}{ Girls } & Internalising problems intercept & 398.5 & 3.3 & $<0.001$ & 53.1 & 1.1 & $<0.001$ \\
\hline & Internalising problems (effects at ages $3,5,7$ ) & 1.8 & 0.8 & 0.034 & -0.4 & 0.3 & 0.097 \\
\hline & Internalising problems (effects at ages 5 and 7) & 1.1 & 0.9 & 0.245 & -0.1 & 0.3 & 0.834 \\
\hline & Internalising problems (effects at age 7) & 1.6 & 0.7 & 0.029 & -0.3 & 0.3 & 0.350 \\
\hline
\end{tabular}

Table abbreviations: MVPA, moderate to vigorous physical activity; SE, standard error.

${ }^{a}$ Adjusted for ethnicity, longstanding illness, BMI, maternal distress, relative poverty (Supplementary unadjusted results are available in eTable2).

Note: Baseline for all models: white, no longstanding illness, $\mathrm{BMI}=8$, Kessler $=0$, above $60 \%$ poverty line, all score variables $=0$. 


\section{Discussion}

\section{Summary of main findings}

We have identified modest associations of behavioural and emotional development with sedentary time in primary (elementary) school-aged children, and weaker and less consistent associations with physical activity, as assessed by MVPA. In cross-sectional analyses at age seven, boys with higher total difficulties scores were less sedentary but not more likely to engage in MVPA. Both boys and girls with higher externalising scores were less likely to be sedentary and more likely to engage in MVPA. Girls with higher internalising scores were more sedentary but not less active, and boys less active but not more sedentary.

Median regression models parameterised according to the life-course approach described in De Stavola et al (2006) allowed estimation of associations between increasing problem scores through early childhood on MVPA and sedentary time measured at age seven. We observed a reduction in sedentary time at age seven in both boys and girls with more total difficulties and more externalising problems. Associations between internalising problems and sedentary time were not found in boys, although in girls higher scores during early-childhood were in general associated with greater sedentariness at age seven. There were positive associations in both boys and girls between time in MVPA and the externalising problem scores. Finally, boys with rising internalising problem scores between ages three and five years were less active at seven years.

\section{Comparisons with other evidence}

Comparison with previously published studies is limited by a lack of consistency between measures used to assess behavioural and emotional development, as well as a paucity of studies using objective measures of MVPA and/or sedentary time. Furthermore, few studies have examined associations between these factors in primary school aged children, an age when between child variation in activity and sedentariness has been documented. We have not identified any studies with repeat measures of behavioural and emotional development in the preschool years: examination of associations with activity and sedentary time using longitudinal measures of child behavioural and emotional development is - to our knowledge novel. This study used SDQ scores as continuous variables instead of using bands to identify children with disorders; this enabled us to investigate associations with the normal spectrum of scores.

Of the available evidence, depression, an internalising problem, has been found to negatively influence activity levels during adolescence (Stavrakakis et al., 2012), supporting our findings in boys. Evidence from cross-sectional studies is more plentiful but such a study design does limit inferences about causality, or the direction of the effects, to be made. Findings from other studies are however generally in agreement with those reported here, notwithstanding methodological differences or differences in the populations studied. Active adolescents are reported to have fewer emotional, behavioural or social problems (Kantomaa, Tammelin, Ebeling, \& Taanila, 2008; Kirkcaldy, Shephard, \& Siefen, 2002), fewer total difficulties (Ussher et al., 2007) and fewer depressive symptoms (Motl, Birnbaum, Kubik, \& Dishman, 2004). Sebire et al. (2011) reported that higher objectively-measured physical activity levels were related to more conduct problems, also measured using the SDQ, and support our results. Gosmann et al. (2015) reported that Brazilian youth with internalising disorders were less active (lower levels of daily energy expenditure), whilst those with externalising disorders had more energy expenditure variability. Similarly, poor emotional wellbeing and difficulties with peers have been found to be associated with more self-reported sedentariness in British youth aged 11 to 12 years (Brodersen et al., 2005), whilst more conduct and hyperactivity problems were associated with higher activity levels. van Egmond-Fröhlich et al. (2012) also found that youth with SDQ-assessed externalising disorders had higher self-reported levels of physical activity. In contrast to our findings, Khalife et al. (2014) reported that children with conduct problems or symptoms of attentiondeficit/hyperactivity disorder (ADHD) were at increased risk of becoming physically inactive adolescents. This discordance with our findings may be explained by the younger age of our sample or Khalife et al.'s use of self-reported activity levels.

\section{Study strengths and weaknesses}

Our study has several methodological strengths. These include longitudinal prospective data based on a large, contemporary and nationally representative sample of children. We stratified 
analyses by sex and examined cross-sectional and distal effects of behavioural and emotional development during early childhood, using the SDQ which has been shown to be a reliable measure of mental health in young people (Goodman \& Goodman, 2011). We recognise that parental recognition and report of problems, especially internalising ones, can be difficult; however, we hope that the use of the broader externalising and internalising subscales in this study, instead of the four individual SDQ subscales, may have reduced measurement error in our exposure variables as they are based on a larger number of SDQ items (Goodman et al., 2010).

We used objective measures of MVPA and sedentary time, which while overcoming the limitations of child or parental report, may underestimate activities not involving vertical movement of the trunk (such as cycling). We also acknowledge that the children in this study were only asked to wear the accelerometer for a single week. If the week had been abnormal for the child in terms of usual activities undertaken, under- or overestimation of activity levels or sedentary time may have occurred and influenced the effect sizes. However, inclusion of children with data for $\geq$ two days, lasting $\geq 10$ hours/day, is considered to provide a reliable estimate of habitual physical activity in large-scale epidemiological studies (Rich et al., 2013a). Whilst we also used validated cut-off points to define the physical intensity thresholds (Pulsford et al., 2011), misclassification may have occurred for children with high externalising problem scores if their scores were affected by marked symptoms of hyperactivity, such as fidgeting and troubles with sitting still. We suspect that fidgeting while seated would not be extensively misclassified as MVPA, but excess movement may have reduced the time registered as sedentary, which is a possible study limitation.

We have not been able to examine trajectories of activity and sedentary time concurrently with behavioural and emotional development trajectories since objective measures with accelerometers were only obtained once at age seven; we were therefore also unable to control for activity levels at the earlier ages.

We have adjusted for a range of confounding factors collected prospectively through early childhood and prior to measurement of the outcome, although we acknowledge that the possibility of residual confounding remains. As there was an interval between the interview at MCS4 and accelerometer measurements, the associations reported here are not truly crosssectional. However the exposure and confounding factors were always measured before the outcome thus providing some support for a causal association.

Our statistical analyses allow inferences to be made to all UK children by using survey weights to adjust for non-response in the MCS surveys as well as the physical activity survey. We fitted median regression models to allow for non-normality in the distribution of daily minutes of sedentary time and MVPA. Finally, we accounted for missing values using multiple imputation under missing-at-random assumptions - this method performs better in terms of bias reduction than other ad hoc procedures, even when data are missing not at random (i.e., non-ignorable or informative missing) (Catellier et al., 2005).

\section{Implications of this research for policy and research}

Our study has identified weak but consistent associations at a population level between behavioural and emotional development in primary school aged children and sedentary time and, to a lesser extent, with MVPA. Different patterns were also observed between boys and girls and for internalising and externalising scores. Identifying these at-risk groups, and the mechanisms underlying these relationships, has relevance for policies that aim to increase activity levels and decrease sedentariness in our youth (Department of Health, 2011; U.S. Department of Health and Human Services, 2008). For example, social intervention programs designed to prevent or treat internalising problems, like therapeutic approaches for emotional symptoms such as unhappiness or nervousness and coping-skills training for children who may experience bullying, may help to reduce sedentariness in young girls by reducing withdrawal from social activities.

Our findings are consistent with Brodersen et al.'s (2005) proposition that physical activity may be an outlet for children with behavioural (externalising) problems. These problems are therefore not detrimental to activity levels per se, although their energetic nature may be developmentally and socially challenging. 
Further longitudinal research should explore relationships in the opposite direction, to evaluate whether activity levels and sedentary time are risk factors for emotional and behavioural development. Studies should also examine more specific internalising and externalising problems, such as hyperactivity and inattention problems, and the influence of other dimensions of physical activity, such as light intensity levels.

\section{Acknowledgements}

The accelerometer data collection was funded by the Wellcome Trust (principal investigator Professor Carol Dezateux) [grant 084686/Z/08/A]. The fourth sweep of the Millennium Cohort Study was funded by grants to Professor Heather Joshi, former director of the study, from the Economic and Social Research Council and a consortium of Government funders. The co-operation of the participating families is gratefully acknowledged as is the contribution of the Centre for longitudinal Studies and others involved in the MCS4 physical activity project fieldwork and data processing and in the creation of the MCS dataset in which it is linked. We are grateful to the UK Data Archive, and Economic and Social Data Service, for making the datasets available. However, they bear no responsibility for the analysis or interpretation of these data. The persistent identifiers of the datasets used in this paper are:

MCS First Survey: http://dx.doi.org/10.5255/UKDA-SN-4683-3;

For MCS2: http://dx.doi.org/10.5255/UKDA-SN-5350-3

For MCS3: http://dx.doi.org/10.5255/UKDA-SN-5795-3

For MCS4: http://dx.doi.org/10.5255/UKDA-SN-6411-5

For Physical Activity: http://dx.doi.org/10.5255/UKDA-SN-7238-1

The Population, Policy and Practice Programme was formed in 2014, incorporating the activities of the Centre for Paediatric Epidemiology and Biostatistics (CPEB). The CPEB was supported in part by the Medical Research Council in its capacity as the MRC Centre of Epidemiology for Child Health (award G0400546). Research at the UCL Institute of Child Health and Great Ormond Street Hospital for Children receives a proportion of the funding from the Department of Health's National Institute for Health Research Biomedical Research Centres funding scheme. The study sponsors played no part in the design, data analysis and interpretation of this study, the writing of the manuscript, or the decision to submit the paper for publication and the authors' work was independent of their funders.

\section{References}

Biddle, S. \& Armstrong, N. (1992). Children's physical activity: an exploratory study of psychological correlates. Social Science \& Medicine, 34, 325-331. http://dx.doi.org/10.1016/0277-9536(92)90274-T

Bradshaw, J. \& Holmes, J. (2010). Child poverty in the first five years of life. In K.Hansen, H. Joshi, \& S. Dex (Eds.), Children of the 21st Century: the first five years. Bristol: The Policy Press. http://dx.doi.org/10.1332/policypress/9781847424761.003.0002

Brodersen, N. H., Steptoe, A., Williamson, S., \& Wardle, J. (2005). Sociodemographic, developmental, environmental, and psychological correlates of physical activity and sedentary behavior at age 11 to 12 . Annals of Behavioral Medicine, 29, 2-11. http://dx.doi.org/10.1207/s15324796abm2901_2

Calfas, K. J. \& Taylor, W. C. (1994). Effects of physical activity on psychological variables in adolescents. Pediatric Exercise Science, 6, 406-423.

Catellier, D. J., Hannan, P. J., Murray, D. M., Addy, C. L., Conway, T. L., Yang, S. \& Rich, J. C. (2005). Imputation of missing data when measuring physical activity by accelerometry. Medicine \& Science in Sports \& Medicine, 37, S555-S562. http://dx.doi.org/10.1249/01.mss.0000185651.59486.4e 
Crocker, P. R., Eklund, R. C., \& Kowalski, K. C. (2000). Children's physical activity and physical self-perceptions. Journal of Sports Science, 18, 383-394. http://dx.doi.org/10.1080/02640410050074313

De Stavola, B. L., Nitsch, D., Dos, S. S., I, McCormack, V., Hardy, R., Mann, V. Cole, T. J., Morton, S. \& Leon, D. A. (2006). Statistical issues in life course epidemiology. American Journal of Epidemiology, 163, 84-96. http://dx.doi.org/10.1093/aje/kwj003

Department of Health. 2011. Start active, stay active: a report on physical activity from the four home countries' Chief Medical Officers. London, Department of Health.

Ekeland, E., Heian, F., \& Hagen, K. B. (2005). Can exercise improve self esteem in children and young people? A systematic review of randomised controlled trials. British Journal of Sports Medicine, 39, 792-798. http://dx.doi.org/10.1136/bjsm.2004.017707

Ekelund, U., Yngve, A., Brage, S., Westerterp, K., \& Sjostrom, M. (2004). Body movement and physical activity energy expenditure in children and adolescents: how to adjust for differences in body size and age. American Journal of Clinical Nutrition, 79, 851-856.

Fairweather, S. C., Reilly, J., Grant, S., Whittaker, A. \& Paton, J. Y. (1999). Using the Computer Science and Applications (CSA) Activity Monitor in Preschool Children. Pediatric Exercise Science, 11, 413-420.

Geraci, M. (2012). pawacc: Physical activity with accelerometers (Version R package version 1.01). Retrieved from: http://r-forge.r-project.org/projects/pawacc

Geraci, M. (2013). Estimation of regression quantiles in complex surveys with data missing at random: An application to birthweight determinants. Statistical Methods in Medical Research, 23. http://dx.doi.org/10.1177/0962280213484401

Geraci, M., Rich, C., Sera, F., Cortina-Borja, M., Griffiths, L. J., \& Dezateux, C. (2012). Technical report on accelerometry data processing in the Millennium Cohort Study. London, UK: University College London. Retrieved from: http://discovery.ucl.ac.uk/1361699

Goodman, A. \& Goodman, R. (2011). Population mean scores predict child mental disorder rates: validating SDQ prevalence estimators in Britain. Journal of Child Psychology and Psychiatry, 52, 100-108. http://dx.doi.org/10.1111/j.1469-7610.2010.02278.x

Goodman, A., Lamping, D. L., \& Ploubidis, G. B. (2010). When to use broader internalising and externalising subscales instead of the hypothesised five subscales on the Strengths and Difficulties Questionnaire (SDQ): data from British parents, teachers and children. Journal of Abnormal Child Psychology, 38, 1179-1191. http://dx.doi.org/10.1007/s10802-010-9434-x

Goodman, R. (1997). The Strengths and Difficulties Questionnaire: a research note. Journal of Child Psychology and Psychiatry, 38, 581-586. http://dx.doi.org/10.1111/j.1469-7610.1997.tb01545.x

Goodman, R., Ford, T., Simmons, H., Gatward, R., \& Meltzer, H. (2000). Using the Strengths and Difficulties Questionnaire (SDQ) to screen for child psychiatric disorders in a community sample. British Journal of Psychiatry, 177:534-9., 534-539. http://dx.doi.org/10.1192/bjp.177.6.534

Gosmann, N. P., Salum, G. A., Schuch, F., Silveira, P. P., Bosa, V. L., Goldani, M. Z. \& Manfro, G. G. (2015). Association Between Internalizing Disorders and Day-to-Day Activities of Low Energetic Expenditure. Child Psychiatry \& Human Development, 46(1):67-74. http://dx.doi.org/10.1007/s10578-014-0450-x

Green, H., McGinnity, A., Meltzer, H., Ford, T., \& Goodman, R. (2004). Survey of the mental health of children and young people in Great Britain, 2004. Palgrave MacMillan; HMSO.

Griffiths, L. J., Cortina-Borja, M., Sera, F., Pouliou, T., Geraci, M., Rich, C. et al. (2013a). How active are our children? Findings from the Millennium Cohort Study. BMJ Open, 3(8), e002893. doi:10.1136/bmjopen-2013-002893. http://dx.doi.org/10.1136/bmjopen-2013-002893

Griffiths, L. J., Rich, C., Geraci, M., Sera, F., Cortina-Borja, M., Pouliou, T., Platt, L., Johnson, J. \& Dezateux, C. (2013b). Technical report on the enhancement of Millennium Cohort Study data with accelerometer-derived measures of physical activity and sedentary behaviour in seven year olds. Retrieved from: http://www.esds.ac.uk/doc/7238/mrdoc/pdf/mcs4_pa_technical_report.pdf

Gruber, J. J. (1986). Physical activity and self-esteem development in children: a meta analysis. Proceedings of the American Academy of Physical Education, 19, 30-48. 
Hansen, K., Jones, E., Joshi, H., \& Budge, D. (2010). Millennium Cohort Study Fourth Survey: A User's Guide to Initial Findings London: Centre for Longitudinal Studies, University of London.

Harden, A., Rees, R., Shepherd, J., Brunton, G., Oliver, S., \& Oakley, A. (2001). Young people and mental health: a systematic review of research on barriers and facilitators. London: EPPI-Centre, Social Science Research Unit, Institute of Education, University of London.

Kantomaa, M. T., Tammelin, T. H., Ebeling, H. E., \& Taanila, A. M. (2008). Emotional and behavioral problems in relation to physical activity in youth. Medicine \& Science in Sports \& Medicine, 40, 1749-1756. http://dx.doi.org/10.1249/mss.0b013e31817b8e82

Kessler, R. C., Andrews, G., Colpe, L. J., Hiripi, E., Mroczek, D. K., Normand, S. L., Walters, E.E. \& Zaslavsky, A.M. (2002). Short screening scales to monitor population prevalences and trends in non-specific psychological distress. Psychological Medicine, 32, 959-976. http://dx.doi.org/10.1017/\$0033291702006074

Khalife, N., Kantomaa, M., Glover, V., Tammelin, T., Laitinen, J., Ebeling, H. Hurtig, T., Jarvelin, M.R. \& Rodriguez, A. (2014). Childhood attention-deficit/hyperactivity disorder symptoms are risk factors for obesity and physical inactivity in adolescence. Journal of the American Academy of Child \& Adolescent Psychiatry, 53, 425-436. http://dx.doi.org/10.1016/j.jaac.2014.01.009

Kirkcaldy, B. D., Shephard, R. J., \& Siefen, R. G. (2002). The relationship between physical activity and self-image and problem behaviour among adolescents. Social Psychiatry and Psychiatric Epidemiology, 37, 544-550. http://dx.doi.org/10.1007/s00127-002-0554-7

Koenker, R. (2012). Quanteg: Quantile Regression R package version 4.79. Retrieved from: http://CRAN.Rproject.org/package=quanteg

Larun, L., Nordheim, L. V., Ekeland, E., Hagen, K. B., \& Heian, F. (2006). Exercise in prevention and treatment of anxiety and depression among children and young people. Cochrane.Database.Syst.Rev., 3, CD004691. http://dx.doi.org/10.1002/14651858.CD004691.pub2

Lumley, T. (2004). Analysis of complex survey samples. Journal of Statistical Software, 9, 1-19. http://dx.doi.org/10.18637/jss.v009.i08

Lumley, T. (2011). Survey: analysis of complex survey samples. $R$ package version 3.26 .

Merikangas, K. R., He, J. P., Brody, D., Fisher, P. W., Bourdon, K., \& Koretz, D. S. (2010). Prevalence and treatment of mental disorders among US children in the 2001-2004 NHANES. Pediatrics, 125, 75-81. http://dx.doi.org/10.1542/peds.2008-2598

Motl, R. W., Birnbaum, A. S., Kubik, M. Y., \& Dishman, R. K. (2004). Naturally occurring changes in physical activity are inversely related to depressive symptoms during early adolescence. Psychosomatic Medicine, 66, 336-342.

Mutrie, N. \& Parfitt, G. (1998). Physical activity and its link with mental, social and moral health in young people. In S.Biddle, J. Sallis, \& N. Cavill (Eds.), Young and active (pp. 49-68). London: Health Education Authority.

National Institute for Health and Clinical Excellence (2008). PH12 Social and emotional wellbeing in primary education. London: National Institute for Health and Clinical Excellence.

Ott, A. E., Pate, R. R., Trost, S. G., Ward, D. S., \& Saunders, R. (2000). The use of uniaxial and triaxial accelerometers to measure children's "free-play" physical activity. Pediatric Exercise Science, 12, 360-370.

Pulsford, R. M., Cortina-Borja, M., Rich, C., Kinnafick, F. E., Dezateux, C., \& Griffiths, L. J. (2011). Actigraph accelerometer-defined boundaries for sedentary behaviour and physical activity intensities in 7 year old children. PLOS ONE, 6, e21822. http://dx.doi.org/10.1371/journal.pone.0021822

Puyau, M. R., Adolph, A. L., Vohra, F. A., \& Butte, N. F. (2002). Validation and calibration of physical activity monitors in children. Obesity Research, 10, 150-157. http://dx.doi.org/10.1038/oby.2002.24

R Development Core Team (2014). R: A language and environment for statistical computing. $R$ Foundation for Statistical Computing, Vienna, Austria. Retrieved from: http://www.R-project.org/

Raustorp, A., Mattsson, E., Svensson, K., \& Stahle, A. (2006). Physical activity, body composition and physical selfesteem: a 3-year follow-up study among adolescents in Sweden. Scandinavian Journal of Medicine \& Science in Sports, 16, 258-266. http://dx.doi.org/10.1111/j.1600-0838.2005.00483.x

Royal College of Paediatrics and Child Health (2013). UK Childhood and Puberty Close Monitoring Growth Chart. http://www.rcpch.ac.uk/improving-child-health/public-health/uk-who-growth-charts/school-age-2-18years/school-age-charts-an\#bmi 
Rich, C., Geraci, M., Griffiths, L., Sera, F., Dezateux, C., \& Cortina-Borja, M. (2013a). Quality control methods in accelerometer data processing: defining minimum wear time. PLOS ONE, 8, e67206. http://dx.doi.org/10.1371/journal.pone.0067206

Rich, C., Cortina-Borja, M., Dezateux, C., Geraci, M., Sera, F., Calderwood, L., Joshi, H., Griffiths, L.J. (2013b). Predictors of non-response in a UK-wide cohort study of children's accelerometer-determined physical activity using postal methods. BMJ Open, 3(3): e002290. http://dx.doi.org/10.1136/bmjopen-2012-002290

Rich, C., Geraci, M., Griffiths, L., Sera, F., Dezateux, C., \& Cortina-Borja, M. (2014). Quality control methods in accelerometer data processing: identifying extreme counts. PLOS ONE, 9, e85134. http://dx.doi.org/10.1371/journal.pone.0085134

Riddoch, C. J., Bo, A. L., Wedderkopp, N., Harro, M., Klasson-Heggebo, L., Sardinha, L. B. Cooper, A.R. \& Ekelund, U. (2004). Physical activity levels and patterns of 9- and 15-yr-old European children. Medicine \& Science in Sports \& Medicine, 36, 86-92. http://dx.doi.org/10.1249/01.mss.0000106174.43932.92

Riddoch, C. J., Mattocks, C., Deere, K., Saunders, J., Kirkby, J., Tilling, K., Leary, S.D., Blair, S.N. \& Ness, A.R. (2007). Objective measurement of levels and patterns of physical activity. Archives of Disease in Childhood, 92, 963969. http://dx.doi.org/10.1136/adc.2006.112136

Sagatun, A., Sogaard, A. J., Bjertness, E., Selmer, R., \& Heyerdahl, S. (2007). The association between weekly hours of physical activity and mental health: a three-year follow-up study of 15-16-year-old students in the city of Oslo, Norway. BMC Public Health, 7, 155. http://dx.doi.org/10.1186/1471-2458-7-155

Sebire, S. J., Jago, R., Fox, K. R., Page, A. S., Brockman, R., \& Thompson, J. L. (2011). Associations between children's social functioning and physical activity participation are not mediated by social acceptance: a cross-sectional study. International Journal of Behavioral Nutrition and Physical Activity, 8. 106. http://dx.doi.org/10.1186/1479-5868-8-106

Smith, K. \& Joshi, H. (2002). The Millennium Cohort Study. Population Trends, 30-34.

Stavrakakis, N., de Jonge, P., Ormel, J., \& Oldehinkel, A. J. (2012). Bidirectional Prospective Associations Between Physical Activity and Depressive Symptoms. The TRAILS Study. Journal of Adolescent Health, 50, 503-508. http://dx.doi.org/10.1016/j.jadohealth.2011.09.004

Troiano, R. P., Berrigan, D., Dodd, K. W., Masse, L. C., Tilert, T., \& McDowell, M. (2008). Physical activity in the United States measured by accelerometer. Medicine \& Science in Sports \& Medicine, 40, 181-188. http://dx.doi.org/10.1249/mss.0b013e31815a51b3

Trost, S. G., Ward, D. S., Moorehead, S. M., Watson, P. D., Riner, W., \& Burke, J. R. (1998). Validity of the computer science and applications (CSA) activity monitor in children. Medicine \& Science in Sports \& Medicine, 30, 629-633. http://dx.doi.org/10.1097/00005768-199804000-00023

U.S.Department of Health and Human Services (2008). 2008 Physical Activity Guidelines for Americans Washington: U.S. Department of Health and Human Services.

Ussher, M. H., Owen, C. G., Cook, D. G., \& Whincup, P. H. (2007). The relationship between physical activity, sedentary behaviour and psychological wellbeing among adolescents. Social Psychiatry and Psychiatric Epidemiology, 42, 851-856. http://dx.doi.org/10.1007/s00127-007-0232-x

Van Buuren, S. \& Groothuis-Oudshoorn, K. (2011). mice: Multivariate Imputation by Chained Equations in R. Journal of Statistical Software, 45, 3, 1-67. http://dx.doi.org/10.18637/jss.v045.i03

Van Der, H. K., Paw, M. J., Twisk, J. W., \& Van, M. W. (2007). A brief review on correlates of physical activity and sedentariness in youth. Medicine \& Science in Sports \& Medicine, 39, 1241-1250. http://dx.doi.org/10.1249/mss.0b013e318059bf35

van Egmond-Frohlich, A. W., Weghuber, D., \& de, Z. M. (2012). Association of symptoms of attentiondeficit/hyperactivity disorder with physical activity, media time, and food intake in children and adolescents. PLOS ONE, 7, e49781. http://dx.doi.org/10.1371/journal.pone.0049781

Wiles, N. J., Peters, T. J., Heron, J., Gunnell, D., Emond, A., \& Lewis, G. (2006). Fetal growth and childhood behavioral problems: results from the ALSPAC cohort. American Journal of Epidemiology, 163, 829-837. http://dx.doi.org/10.1093/aje/kwj108 


\section{Appendix}

\section{Supplementary tables - unadjusted results}

eTable1: Unadjusted results of median regression cross-sectional analyses. Estimates and standard errors are expressed as minutes per day per unit SDQ score.

\begin{tabular}{|c|c|c|c|c|c|c|c|}
\hline & & \multicolumn{3}{|c|}{ Sedentary time } & \multicolumn{3}{|c|}{ MVPA } \\
\hline & & Estimate & SE & $p$-value & Estimate & SE & $p$-value \\
\hline \multirow[t]{2}{*}{ Boys } & Intercept & 399.0 & 2.5 & 0.000 & 274.7 & 1.6 & 0.000 \\
\hline & Total difficulties (age 7) & -1.1 & 0.3 & 0.000 & 0.7 & 0.2 & 0.000 \\
\hline \multirow[t]{2}{*}{ Girls } & Intercept & 389.3 & 1.8 & 0.000 & 274.9 & 2.0 & 0.000 \\
\hline & Total difficulties (age 7) & -0.8 & 0.2 & 0.001 & 0.8 & 0.3 & 0.002 \\
\hline \multirow[t]{2}{*}{ Boys } & Intercept & 402.7 & 1.7 & 0.000 & 272.7 & 1.2 & 0.000 \\
\hline & Externalising problems (age 7) & -2.5 & 0.3 & 0.000 & 1.6 & 0.2 & 0.000 \\
\hline \multirow[t]{2}{*}{ Girls } & Intercept & 392.2 & 2.3 & 0.000 & 273.4 & 1.7 & 0.000 \\
\hline & Externalising problems (age 7) & -1.7 & 0.4 & 0.000 & 1.6 & 0.3 & 0.000 \\
\hline \multirow[t]{2}{*}{ Boys } & Intercept & 388.9 & 1.5 & 0.000 & 280.4 & 1.2 & 0.000 \\
\hline & Internalising problems (age 7) & 0.7 & 0.3 & 0.031 & -0.1 & 0.3 & 0.694 \\
\hline \multirow[t]{2}{*}{ Girls } & Intercept & 383.3 & 1.8 & 0.000 & 281.3 & 1.6 & 0.000 \\
\hline & Internalising problems (age 7) & 0.1 & 0.7 & 0.891 & 0.1 & 0.4 & 0.730 \\
\hline
\end{tabular}

Table abbreviations for eTable1 and eTable 2: MVPA, moderate-to-vigorous physical activity; SE, standard error. 
eTable2: Unadjusted results of median regression analyses with sedentary behaviour and physical activity as distal outcomes. Estimates and standard errors are expressed as minutes per day per unit SDQ score.

Sedentary time

MVPA

\begin{tabular}{|c|c|c|c|c|c|c|c|}
\hline & & Estimate & SE & $p$-value & Estimate & SE & $p$-value \\
\hline \multirow[t]{4}{*}{ Boys } & Total difficulties intercept & 391.4 & 3.5 & 0.000 & 274.5 & 2.5 & 0.000 \\
\hline & Total difficulties (sum of conditional effects at ages $3,5,7$ ) & -0.9 & 0.4 & 0.013 & 0.9 & 0.3 & 0.003 \\
\hline & Total difficulties (sum of conditional effects at ages 5 and 7) & -0.6 & 0.3 & 0.052 & 0.8 & 0.3 & 0.013 \\
\hline & Total difficulties (conditional effect at age 7) & -0.8 & 0.3 & 0.010 & 0.6 & 0.4 & 0.094 \\
\hline \multirow[t]{4}{*}{ Girls } & Total difficulties intercept & 408.7 & 3.6 & 0.000 & 271.7 & 2.2 & 0.000 \\
\hline & Total difficulties (sum of conditional effects at ages $3,5,7$ ) & -1.2 & 0.5 & 0.016 & 1.0 & 0.3 & 0.003 \\
\hline & Total difficulties (sum of conditional effects ages 5 and 7) & -0.6 & 0.6 & 0.299 & 0.7 & 0.4 & 0.084 \\
\hline & Total difficulties (conditional effect at age 7) & 0.4 & 0.6 & 0.567 & -0.1 & 0.4 & 0.739 \\
\hline \multirow[t]{4}{*}{ Boys } & Externalising problems intercept & 395.7 & 3.4 & 0.000 & 272.7 & 2.2 & 0.000 \\
\hline & Externalising problems (effects at ages $3,5,7$ ) & -2.1 & 0.6 & 0.000 & 1.6 & 0.4 & 0.000 \\
\hline & Externalising problems (effects at ages 5 and 7) & -1.4 & 0.5 & 0.007 & 1.3 & 0.5 & 0.005 \\
\hline & Externalising problems (effects at age 7) & -1.3 & 0.6 & 0.025 & 1.2 & 0.5 & 0.012 \\
\hline \multirow[t]{4}{*}{ Girls } & Externalising problems intercept & 415.0 & 2.6 & 0.000 & 268.3 & 2.4 & 0.000 \\
\hline & Externalising problems (effects at ages $3,5,7$ ) & -3.0 & 0.5 & 0.000 & 2.1 & 0.6 & 0.000 \\
\hline & Externalising problems (effects at ages 5 and 7) & -1.8 & 0.7 & 0.015 & 1.5 & 0.7 & 0.024 \\
\hline & Externalising problems (effects at age 7) & -0.7 & 0.9 & 0.401 & 0.5 & 0.5 & 0.356 \\
\hline \multirow[t]{4}{*}{ Boys } & Internalising problems intercept & 380.9 & 2.1 & 0.000 & 281.8 & 1.9 & 0.000 \\
\hline & Internalising problems (effects at ages $3,5,7$ ) & 0.9 & 0.6 & 0.119 & 0.0 & 0.6 & 0.956 \\
\hline & Internalising problems (effects at ages 5 and 7) & 0.5 & 0.7 & 0.463 & 0.1 & 0.6 & 0.889 \\
\hline & Internalising problems (effects at age 7) & -0.6 & 0.8 & 0.406 & 0.2 & 0.5 & 0.756 \\
\hline \multirow[t]{4}{*}{ Girls } & Internalising problems intercept & 396.3 & 2.7 & 0.000 & 279.8 & 2.4 & 0.000 \\
\hline & Internalising problems (effects at ages $3,5,7$ ) & 1.3 & 0.9 & 0.145 & -0.4 & 0.8 & 0.560 \\
\hline & Internalising problems (effects at ages 5 and 7) & 0.9 & 1.0 & 0.373 & -0.2 & 0.8 & 0.784 \\
\hline & Internalising problems (effects at age 7) & 1.1 & 0.8 & 0.168 & -0.8 & 0.6 & 0.157 \\
\hline
\end{tabular}

